\title{
Web 2.0: challenges and opportunities for media education and beyond
}

\author{
CHI-KIM CHEUNG \\ Faculty of Education, University of Hong Kong
}

\begin{abstract}
The nature of knowledge is being redefined by a new media landscape that allows all participants to be media producers and owners. Without a comprehensive strategy to include Web 2.0 tools and social media practices within schools, powerful new skills will be neither harnessed, nor developed. Despite the challenge to the relationship between students (digital natives) and teachers (digital immigrants) that Web 2.0 tools present, teachers are still the vital link to supporting students and giving meaning to the practices they engage in, including developing critical thinking in an information age. This article discusses the challenges and opportunities presented to media education by Web 2.0 tools and social media practices and vice versa. Consistently, it can be demonstrated that these symbiotic potentials are reflected beyond the microcosm of media education in schools. Future performance at work and functioning within a global economy and the effect of collaborative networking skills on local, national and global societies go further than the challenge to school curricula. Local specific effects of 'co-learning' and the new status of 'learner voice' on learning experiences show the beginnings of a gradual influence that has far-reaching potentials.
\end{abstract}

\section{Introduction}

Humans are social beings and what makes the new media landscape such a powerful force in today's society is the way people have taken the new technologies and breathed life into them, making unique social and cultural interconnected spaces. As holism is bringing together previously disconnected theories and concepts in science and medicine, the concept also lends itself perfectly to Web 2.0 social media environments. We are not just the sum of our individual blogs. The collective social media environment, created by Web 2.0 tools, is challenging the concept of information and interpretation, presenting a whole new culture of meaning and participation. What makes media education in the era of Web 2.0 so exciting is that finally teachers now have the opportunity to say to today's digital natives, yes you know more than us about some of these things, but let's work together to make your understanding stronger: you lead us, and we'll show you the way. Students are now in the driving seat, as adults, today's digital immigrants, concede to the new wave of peer-to-peer informal media production that is creating such a pervasive social and cultural force. If these new skills can be harnessed in the right way, the potential exists to make this and future generations better equipped than ever before to function in public, economic and community life. Better than that, by challenging student media producers now and building a growing awareness of individual agency plus global connectedness, a move towards a more connected world could be made using the adage: we are all different, yet the same.

\section{Beyond the Technical: new media literacies and participatory culture}

A summary of a youth media education survey carried out by UNESCO in 2001 (Domaille \& Buckingham, 2001) implied that new developments in media education were expected through the 
use of information and communications technology (ICT) in schools. It was proposed that the theory and practice of media education in schools would be reconfigured and that this would have an impact also on critical thinking in relation to ICT. It was suggested that greater competence with the relevant technologies in general could result in the development of a more formal media education curriculum.

A more recent White Paper on media education and an emerging participatory culture (Jenkins et al, 2006) highlights that the media skills and practices that have grown up around the era of Web 2.0 and that have such a central role in the lives of children and young people today present a more complex relationship than simply ICT and media education. The White Paper suggests that this participatory culture is happening now and will happen regardless of media education, making it a critical time to shape what is offered in schools around current social media practices. In short, rather than building a media education curriculum around the available technology, the existence of emerging new media literacy skills and participatory practices needs to be acknowledged now, and a media education framework provided in schools to suit these, to guide students through the new media landscape (Cheung, 2009a).

It is vital then that media education, rather than ICT, is presented with the challenge and task of providing a supportive framework within which students can explore new media literacies. In this sense, Jenkins et al (2006) highlight 'the importance of coupling the pedagogical use of new media technologies with a greater focus on media literacy education' (p. 15). They go further to suggest that as well as the expansion of skills that these new media literacies encourage, collectively they should be considered as a new set of social skills and cultural competencies.

These new skills go further than pushing the boundaries of individual expression. Access to a wider community through Web 2.0 is pushing the creation and interpretation of information into a social sphere where the social production of meaning and collective intelligence is now impacting on 'the ways we make sense of cultural experience' (Jenkins et al, 2006, p. 20). This in turn creates a unique opportunity for collaboration, creation and understanding across local and global boundaries; within and between learning communities.

The new participatory culture is characterised by empowerment. New technology is empowering children and offering new ways of sharing and interacting with their peers (Heim et al, 2007). In a society where traditional divisions are still apparent, the use of computers in schools gives opportunities for group and social interaction and friendship formation that may not have occurred before. What happens in schools on a local basis can also transcend physical boundaries, forming the participatory trend and global cultural understanding that Jenkins et al (2006) allude to.

Kellner (2002) also suggests that focusing on new media literacies as a set of skills and cultural competencies in schools will also help to democratise the effects of new media technology in society in general. Teaching new media literacies in schools has wide-reaching extensions: the promotion of 'a healthy multiculturalism of diversity' (Kellner, 2002, p. 6). Successful participatory activity on any level, local or global, relies on the acceptance of differences between the participants. Developing this in schools will empower students to engage with the new participatory culture on all levels.

\section{Reconciling a 'Google Generation’ with Formal Media Education}

There is much debate surrounding the use and application of Web 2.0 tools in education. This broadly covers the impact of the social nature of Web 2.0 on learning and whether formal education is supported or undermined by the use of Web 2.0 in schools (Selwyn, 2006). Researchers are currently looking at all the angles: the use of Web 2.0 by students outside of school and how this impacts on their learning in school (Kent \& Facer, 2004); how Web 2.0 helps to develop new literacies (Jenkins et al, 2006) and critical thinking, or whether Web 2.0 is creating a 'Google Generation' of students incapable of independent or critical thought (Brabazon, 2007).

There are undoubted educational potentials of Web 2.0 but the unique reciprocities between education and Web 2.0 need first to be made clear, so that new processes can be identified, before the job of embedding them can begin. This will need to happen in order to capture the minds of digital natives in schools today in relation to the 'offline realities of their formal education' (Selwyn, 2006, p. 11) and to set up the structure for the future of media education in schools, harnessing the 
potential of social media for creating new learning concepts: 'collaboration, publication, literacies and inquiry' (Selwyn et al, 2006, p. 24).

The effects on young people of their use of Web 2.0 tools are so pervasive; Jenkins et al (2006) predict that academic success will rely as much on ability in new media literacies as on ability in other more traditional subjects. A 'hidden curriculum' (Jenkins et al, 2006, p. 3) is having a greater effect right now on young people than is recognised in schools and it is this argument that most commentators agree is the biggest justification for building on the potential of Web 2.0 for media education. Not having access to this informal curriculum could mean the difference between successfully developing new media literacy skills and confidence in participatory activities, and being able to succeed in the future at work, as an empowered citizen, or a future learner.

\section{Media Education and Web 2.0: a match made in cyber heaven}

Web 2.0 is influencing information and knowledge creation not just as a media message, but also as a 'next generation' cultural revolution (Cheung, 2009b). Media education needs to address the theory and practices behind the user-generated information culture and the potential this has for students as media producers and participants. At the same time, Web 2.0 will necessarily impact on media education in a much broader way in terms of how it is presented in schools and the curriculum in general.

A significant technological revolution is on the horizon, which will put pressure on the need for 'new curricula, pedagogy, literacies, practices and goals' (Kellner, 2002, p. 2). Kellner also comments on the impact of new media technology on teacher training and technology policies within schools, as well as the need for 'an expanded concept of literacy to respond to the importance of new media and technologies in every aspect of life' (p. 3). Perhaps one of the most significant impacts of Web 2.0 on media education is how it will demand a restructuring of the relationship between teachers and students and project that link to a wider cultural and social environment.

Technological advances and the significance of usability, accessibility and individualisation have created a less hierarchical knowledge society where individuals as well as organisations are creating knowledge using Web 2.0 tools. By engaging students in these practices early on, they are being prepared and equipped for later life as knowledge workers in a global information society.

'Social software is not a trend that can be ignored', states Nielson (2009) in a study looking at how social networking on intranets is creating 'Enterprise 2.0' (the use of Web 2.0 tools in business), through younger workers transferring their skills from their social sphere to work. Elaborating, Nielson touches on the importance of using Web 2.0 tools for communication in the workplace: 'It's affecting fundamental change in how people expect to communicate, both with each other and the companies they do business with'.

The impact of Web 2.0 on face-to-face communication and the ability to work collaboratively in teams towards a collective intelligence is well documented (Redecker et al, 2009). Collective intelligence, as well as giving grassroots power to groups, is starting to be harnessed by governments and companies. Putting the collaborative skills learnt in school into practice in the workplace will enable students to benefit from the empowerment of their own knowledge contributing to the strength of the whole, be it in terms of business ideas, workplace strategies or to support the interests of employees in general.

Media education is on the cusp of an opportunity to reach the participants of a new media culture at a formative stage, while the convergence of ICT and education in a lifelong learning context provides scope for individuals to use their skills throughout their lives in a variety of informal and formal learning settings. Web 2.0 and media education have a symbiotic potential: Web 2.0 tools can offer as much to the design and status of media education as media education can offer learners in the era of Web 2.0.

\section{Semantic Web and Social Web: order out of chaos}

The accessibility of Web 2.0 spaces redefines current information and communication models. The self-sufficiency and organic nature of social web communities mean that information flows more 
easily from centre to periphery and vice versa. Crook (2006) describes the 'emergent patterns of communication' (p. 6) in the network effects of 'a large, always-on population of users' (p. 6).

The semantic web (Web 3.0), rather than replacing Web 2.0, reflects the time-honoured tradition of applying science to natural processes in order to understand them and control them to our collective advantage. In this sense, semantic and social web are seen as working together, the semantic web helping to organise the ever-increasing contribution of human participation in an online world.

In an educational context, a partnership between social and semantic web would create a space 'open to be filled with meaning' (Carmichael, 2006, p. 22). The potential of the semantic web for learning means teacher and learner engagement would be fluid, flexible and generative (Koper, 2004). This and the implications of a more personalised environment for learning are only starting to be realised from a Web 2.0 perspective.

A system that responds to the learner, rather than the other way around, opens up opportunities for learners as individuals with different forms of skills and knowledge, and for 'learner focused forms of assessment and feedback' (Green et al, 2005, p. 3). Green et al's report on digital technologies and personalisation acknowledges that learners are already creating for themselves a personalised learning environment, and that a 'systemic change' (p. 4) is needed in schools to reshape education around the learner as part of the impact of digital technologies in use today. What Web 3.0 will offer media education is a way of further customising that personal environment, for example by being able to search aggregated content in a newly definable way.

Web 2.0 is pointing us towards a cultural and social shift and the semantic web will help the collective knowledge that arises from these practices to be categorised and put to better use. The potential for learners is that data will become more 'authentic' and teachers can draw from a wider resource base to present information to students. It may be that the semantic web will help to convince educators of the value of applying social web techniques to educational practices. Creating structure out of unstructured data (Gruber, 2006), the process underlying the partnership between social and semantic web, perhaps demonstrates a robustness that social web practices alone do not. Fundamentally though, it is the social practices and collective output from the use of Web 2.0 tools that provide the basis for this organisation of collective intelligence.

\section{Students Rule: a student-centric approach to media education}

A large part of the concept of a student-centric approach to media education rests on the assumption that through an increase of choice in learning will come an increased sense of responsibility and ownership. Students, given more control over what they are learning and how they are learning it, have the potential to create a shift where it becomes necessary to:

reshape the education system around the learner and to enable the learner's voice to be heard more powerfully in shaping the curriculum, contexts and practices of their learning both in and out of schools. (Green et al, 2005, p. 7)

The personalisation of learning through the use of Web 2.0 tools means that students can actively build on their own skills, knowledge and interests using tools that are familiar to them and accessible in multiple environments and at the same time develop into areas, ideas or networks that are more unfamiliar, through active participation. Students can become active media producers through the acts of creation, collaboration and communication. This new kind of learning through personalisation and collaboration will have a significant effect on students because they will be able to make sense of their world through the tools that are increasingly creating it. Society as a whole will benefit from this type of empowered learning, as students become adults and find their place in the world of civic life and work (Hague \& Williamson, 2009).

Web 2.0 tools provide an opportunity for media education by providing active, collaborative spaces that encourage the creative expression of ideas. This provides a new educational landscape for students who now perceive and understand themselves as participants in the creation and production of ideas. There is a shift from the passive consumption of information to an empowerment through becoming part of a digital historiography, through the creation and manipulation of information and digital artefacts (Anderson, 2007). 
Providing a student-centred focus to media education will necessarily redefine what the goals of media education are. Using blogs or other social media tools will change student expectations of what they are going to learn and how they are going to learn it. This creates opportunities from a pedagogical point of view, summed up by Jenkins et al $(2006$, p. 4) as the new core media literacy skills:

Play, performance, simulation, appropriation, multitasking, distributed cognition, collective

intelligence, judgement, transmedia navigation, networking and negotiation.

Central to the development of these new skills is the need for collaboration and networking, making the individual student and his or her peers the agents, rather than the passive recipients of, learning.

A holistic model of media education (Lee \& Mok, 2007) necessarily places the student at its centre, because it is the individual student creator of the iterative collective intelligence who is producing new social meanings, and it is these meanings that are creating their cultural understanding of the world around them. Individual ideas and knowledge that are socially and culturally construed via new media tools create the collective intelligence that is creating meaning in today's media landscape. Progress and change is attributable to the individual student as much as anything else - another empowering factor of the Web 2.0 media landscape.

\section{Non-linear Education: how Web 2.0 questions formal education}

Using Web 2.0 tools encourages 'learning by doing' in a more informal way, encouraging originality and individuality. This raises the question of how Web 2.0 will influence formal methods of learning.

Web 2.0 tools and social media are moving education towards the form described by Anderson (2007) as follows: 'conversation and learning content is something you perform some kind of operation on rather than "just" reading it' (p. 32). A significant change in how knowledge is now being acquired can be demonstrated by the example of typing in key words to generate multiple results, as opposed to just reading textbooks. By learning to use information from different sources, students will become aware of 'how technology and media affect the ways in which we go about finding things out' (Hague \& Williamson, 2009, p. 5). This also encourages students to communicate with each other, to question conflicting facts, and to build shared knowledge and understanding. In providing a new space for the development and expression of individual ideas, Web 2.0 tools provide an opportunity to move away from more linear forms of learning, encouraging the formation of new ideas and challenging the boundaries and provisions associated with formal education.

Kent \& Facer (2004) propose that due to the 'portability of social practices from school to home' (p. 452), the boundaries of education are becoming blurred. This also contributes to the challenge presented to the current relationship between teachers and students as students' learning is enhanced by a sense of autonomy and creativity and the fact that 'teachers can learn from students and that often students are ahead of teachers in various technological literacies and technical abilities' (Kellner, 2002, p. 16). Home is now a place where ideas can be embedded and work can be done to meet the criteria set by the curriculum, through access to resources at home and the access to the social networking support that the internet provides. The fact that children are learning prolifically at home raises a fundamental issue with formal education, which can be seen as disconnected from 'students' experiences, subjectivities, and interests rooted in the new multimedia cyberculture in contrast to the classroom situation' (Kellner, 2002, p. 16). This again reinforces the need for a student-centric approach to media education, one that supports individual development that goes on elsewhere, including in the home.

Classrooms and lessons are often restricted by structural factors, including access rights and control: 'young people are felt to be turning to Web 2.0-based forms of learning in spite of - rather than because of - their educational institutions' (Selwyn, 2006, p. 11). In a study on home and school ICT use, students complained of the effect of time constraints on the productiveness of school ICT lessons, slow computers and slow loading times of web pages (Kent \& Facer, 2004). Technology and systems in schools that are perceived to be obstructive to the creative learning process that students are used to outside of the school environment further disconnect students 
from a positive learning experience in school. Schools need to support an interactive learning experience so that students can share and build on their skills and knowledge with their peers and teachers. Personalised learning is more likely to take place during out-of-lesson access to computers when students can have the freedom to interact and develop ideas. In these environments, children are learning and experimenting with new media and in a sense are excluded from the formal systems that might otherwise be unintentionally constraining their activities and development. Children can explore their creative and critical capacities through new media technologies with an autonomy that is currently not possible in lessons and even at home, where parents may be monitoring or restricting their use of new media.

The change that Jenkins et al (2006) describe does not stop at the impact on children's learning and development through the informal use of new media literacies. This change is more far-reaching, having a ripple effect on self-concept and place in society. In fact, new media technologies may now have a greater influence on socialising children than parents and schools. Having access to the internet and Web 2.0 tools at home means that learning can now happen continuously between schools and home. Home is not just a place to do homework, but can be an extension of the lesson of the day and a place where ideas can be developed and honed. Lessons will need to be structured to take into account the more dynamic practices of learning that Web 2.0 tools support and the activity that has happened off site in the student's own time. Lessons given in a linear and rigid format will not take into account the many different exchanges and learning curves that would normally be occurring when students are learning individually and in connection with peers as part of the new participatory culture. Collaborative practices will need to be introduced into the classroom to provide students the support they need to interpret their own social media practices.

Having the choice to participate may now be the significant reason why so many young people are being engaged by Web 2.0 tools and practices. Students are functioning on a new level of autonomy through choice. Far from undermining formal and traditional education practices, the choices that Web 2.0 tools present to students, most notably the choice to participate, have potential for increasing student engagement.

\section{Peer-to-Peer Networking: the bottom-up revolution}

Digital natives have grown up in a networked society. This usually means that children are the experts at home, often helping to teach older siblings and parents how to use Web 2.0 tools. Students are also becoming more used to interacting with their peers, providing feedback and opinion and even taking on the role of 'expert and teacher' at the same time.

Peer-to-peer collaboration is already happening on a large scale in affinity spaces. These spaces, Gee (2004) says, prove to be such prolific arenas of informal collaboration and learning because they are sustained by common endeavours that bridge differences in age, class, race, gender and educational background. Jenkins et al (2006) go on to say that these knowledge cultures need to be integrated into schools, not just on a local level, but through 'long distance collaboration across different learning communities' (p. 21).

Web 2.0 has created a new media landscape, with its own tools and practices. The need for media education in the era of Web 2.0 is significant in the sense that fundamental boundaries are being challenged by the new technologies and local/regional/global boundaries are being created or re-created. The effects of this new landscape should not be underestimated. Just as a networked, virtual world creates a 'levelling effect' (Crook, 2006, p. 7) amongst online retailers, information of all kinds is now more easily available, implying 'emancipation, empowerment and participation' (p. 7).

Web 2.0 can help with the building of classroom communities, bringing existing peer-to-peer networks into an educational environment. Current research with undergraduate students shows that if students are involved in setting these up themselves, they are likely to be more effective than those that are formally set up by a lecturer (Selwyn, 2006). Classroom communities need to be based on the new media and cultural spaces that students are conversant with, bringing new media education fully into the new technological and information age. 


\section{Web 2.0: developing critical thinking in media education}

Web 2.0 presents a new challenge to media education as it is changing the "perception of who has the authority to "say" and "know"' (Anderson, 2007, p. 15). Providing a basis for active engagement with and the production of new materials, Web 2.0 tools also provide a new framework for working with ideas: flexibility, immediacy, open access, and new ways of organisation of information, exchange of ideas, updates and progress, and group work.

The new ways of working that Web 2.0 tools provide mean students not only study a subject; they learn different ways of learning how to study that subject. Students 'need these different kinds of skills, knowledge and understanding to develop their expertise in all of the subjects' (Hague \& Williamson, 2009, p. 5), because as the world is changing, knowledge about the world needs to change too. Digital literacy can be seen as a set of 'life skills' that help to extend students' knowledge beyond the classroom, helping them to make sense of the world as it is shaped and changed by a new media landscape.

Despite the possibilities presented to students through using Web 2.0 tools, students need support in identifying and using their new thinking skills. As noted by Wegerif (2002): 'Using technology does not, by itself, lead to transferable thinking skills' (p. 3). If students receive adequate guidance through the critical maze presented to them through access to the ever-increasing diversity in source materials, the effects of this new relationship with media can promote critical thinking through the increase in reflection through personal production.

Media education and Web 2.0 provide a unique opportunity to immerse students in active media production that provides links between themselves, their ideas and either guided contemporary issues or their own social and creative networks. A positive feedback loop is created between knowledge creation and the ownership of ideas. Through their own media practices, and by exposure to a media landscape that is fluctuating, conflicting, progressive and relentless, students become media literate and 'skillful in analyzing media codes and conventions, able to criticize stereotypes, values, and ideologies, and competent to interpret the multiple meanings and messages generated by media texts' (Kellner, 2002, p. 6).

The functions and format of Web 2.0 mirror mind maps and give a visual representation of ideas and the linking of ideas. Locating the student at the centre of the media experience, rather than the periphery, empowers the student to take a 360-degree viewpoint of concepts and how they might interlink. Students are at the centre of an individual and unique mind map that connects and intertwines with countless others. By raising the status of media education using Web 2.0 tools, students can have access to a new collaborative and dynamic lens through which current media themes and ideologies can be analysed; they will then develop divergent and critical thinking skills that ultimately will be applicable across contexts.

\section{Beyond Traditional Curriculum and Assessment}

The development of new media literacies poses a challenge for the formal curriculum to support these skills and provide a framework so that students can understand social media and Web 2.0 tools in an educational context. This also raises the question of how these new skills and competencies will be assessed.

Web 2.0 tools also present opportunities for assessment. Students can complete tasks using a software system dedicated to assessment for learning, which allows them to see their progress visually through charts and colour coding. Teachers can easily see how each student is progressing and give more personalised feedback. More dynamic support for creative written work, for example, can also come out of using similar collaborative tools.

Schools will discover that in making the move towards using Web 2.0 tools and creating learner-directed strategies, they are supported by fields that reach further than the individual school curriculum and strategy, for example the advances in educational research brought about by the multidisciplinary approaches of sociology, semiotics, and policy (John, 2007). There are also several examples of 'trailblazer' schools that can provide good examples of innovative ways to push the curriculum forward. 


\section{The Status of Media Education in a New Media Landscape}

Web 2.0 offers a combination of unique technological aspects and socio-cultural opportunities that develop students into citizens capable of contributing to the emerging social, cultural, economic and political contexts of their futures. Media education in schools, and the use of Web 2.0, provide the opportunity to engage these future citizens now, to better prepare them for success in a knowledge-based society.

Web 2.0, collaboration and joint production are becoming embedded as essential skills within and throughout the structure of organisations and are fast becoming the defining factors of current organisational knowledge creation and management practices. Not only will students need to be able to participate in digital practices at work, they will need to be able to think carefully about what they are participating in and how the terms of their participation may be constrained or limited by commercial, social, political or ideological factors' (Hague \& Williamson, 2009, p. 25). Media education geared towards a new media landscape prepares students to be discerning in the world of work, as well as improving their chances of getting a good job.

A partnership between Web 2.0 and media education will not only support skills currently proposed as important for participation in today's global economy, but also collaboration between people with diverse cultural backgrounds. Restructuring and prioritising media education in schools so that it is available to all will help to ensure that improvements in cultural and social capital attributable to mastering new media literacies are not skewed against groups in society that consistently find themselves unable to cross an invisible line, due for example to class or race.

Opening up the new media landscape to the full potential of diversity in society through new media education in schools builds on previous efforts to close the digital divide. Society's divisions could be transformed by the empowerment of traditionally excluded groups, not least through the collaboration of students who learn that diversity is a strength and not a weakness.

The majority of commentators on the subject of Web 2.0 and education state the need for greater responsiveness towards the needs of students and the opportunities for the personalisation of learning that Web 2.0 (and 3.0) tools bring. Perhaps students should be engaged to provide the lead in the creation of a new curriculum for Web 2.0 and media education.

The personalisation of learning in schools opens up opportunities for the status of media education in general - given the positive correlation between giving greater decision-making powers to students and engagement levels. The challenge for schools in the future is to understand that the personalisation of learning must be led by learners themselves and it is new media tools that give a perfect context for the increased ownership of subject matter and content, which makes for more effective learning.

\section{Conclusion}

Now is a time when schools have to adapt to the rapid changes in technology. This digital world gives easy access to words, sound, images, and moving images in volumes and speed. What is more, people can participate and interact. It is no longer the case that students have to rely solely on teachers for information. The nature of knowledge is being redefined by a new media landscape that allows all participants to be media producers and owners. Digital natives have something to teach educators and young people are in a position now more than ever before to contribute to the systems and processes that they are part of. Without a comprehensive strategy to include Web 2.0 tools and social media practices within schools, powerful new skills will be neither harnessed, nor developed.

The wider global impacts that this sense of connectedness through shared social and cultural media practice can only be alluded to at this stage. Those who are sceptical can find reassurance in reported specific local effects. A new form of 'mutual respect' between teachers and students has been found to accompany the introduction of more collaborative and interactive educational experiences.

It can be said then that the new methods of co-learning that new media tools offer, the dialogic approach to teaching and learning and the new status given to 'learner voice' (Thomas, 2009) are pointing towards not just new trends in education and learning, but an evolved concept 
of democratic education, empowering young people in a society that is notable as much for its pervading divisions, as it is for its potentials for new unions.

\section{References}

Anderson, P. (2007) What is Web 2.0? Ideas, Technologies and Implications for Education, JISC Technology and Standards Watch, February, 1-64.

Brabazon, T. (2007) The Google Generation. Aldershot: Ashgate.

Carmichael, P. (2006) Web 2.0 - future issues and technologies. In Education 2.0? Designing the Web for Teaching and Learning. Institute of Education, London. Teaching and Learning Research Programme website. http:/ / www.tlrp.org/pub/documents/TELcomm.pdf

Cheung, C.K. (2009a) Media Education across Four Asian Societies: issues and themes, International Review of Education, 55, 39-58. http:/ / dx.doi.org/10.1007/s11159-008-9111-2

Cheung, C.K. (2009b) The Significance of Media Education: current realities and future possibilities, in C.K. Cheung (Ed.) Media Education in Asia. New York: Springer.

Crook, C. (2006) What are Web 2.0 Technologies, and Why Do They Matter? in Education 2.0? Designing the Web for Teaching and Learning. Institute of Education, London. Teaching and Learning Research Programme website. http:/ / www.tlrp.org/pub/documents/TELcomm.pdf

Domaille, K. \& Buckingham, D. (2001) Youth Media Education Survey 2001. Paris: UNESCO.

Gee, J.P. (2004) Situated Language and Learning: a critique of traditional schooling. New York: Routledge.

Green, H., Facer, K., Rudd, T., Dillon, P. \& Humphreys, P. (2005) Personalisation and Digital Technologies. Bristol: Futurelab.

Gruber, T. (2006) Where the Social Web meets Semantic Web. VideoLectures.Net website. http:/ / videolectures.net/iswc06_gruber_wswms/

Hague, C. \& Williamson, B. (2009) Digital Participation, Digital Literacy and School Subjects. Bristol: Futurelab.

Heim, J., Brandtzaeg, P.B., Hertzberg Kaare, B., Endestad, T. \& Torgersen, L. (2007) Children's Usage of Media Technologies and Psychosocial Factors, New Media and Society, 9, 425-454. http: / / dx.doi.org/ 10.1177/1461444807076971

Jenkins, H., Purushotma, R., Clinton, K., Weigel, M. \& Robison, A.J. (2006) Confronting the Challenges of Participatory Culture: media education for the 21st century. Chicago: Macarthur Foundation.

John, M. (2007) Stepping Out into Learning with Digital Technologies: the London Knowledge Lab. Bristol: Futurelab.

Kellner, D. (2002) New Media and New Media Literacies: reconstructing education for the new millennium, in L. Lievrouw \& S. Livingstone (Eds) The Handbook of New Media. Los Angeles: Sage.

Kent, N. \& Facer, K. (2004) Different Worlds? A Comparison of Young People's Home and School ICT Use, Journal of Assisted Learning, 20, 440-455. http: / dx.doi.org/10.1111/j.1365-2729.2004.00102.x

Koper, R. (2004) Use of the Semantic Web to Solve Some Basic Problems in Education: increase flexible, distributed lifelong learning, decrease teacher's workload, Journal of Interactive Media in Education, 6, 1-23.

Lee, A. \& Mok, E. (2007) Media Education in Post-colonial Hong Kong: cultivating critical young minds, in A.T. Nowak, S. Abel \& K. Ross (Eds) Media Education as Pedagogy: essays on identity and critical thinking. Cresskill: Hampton Press.

Nielson, J. (2009) Social Networking on Intranets. Useit.com website. http: / / www.useit.com/alertbox/social-intranet-features.html

Redecker, C., Ala-Mutka, K., Bacigalupo, M., Ferrari, A. \& Punie, Y. (2009) Learning 2.0: the impact of Web 2.0 innovations on education and training in Europe. Luxembourg: European Commission.

Selwyn, N. (2006) Educational Hopes and Fears for Web 2.0, in Education 2.0? Designing the Web for Teaching and Learning. Institute of Education, London. Teaching and Learning Research Programme website. http: / / www.tlrp.org/pub/ documents/TELcomm.pdf

Selwyn, N., Crook, C., Noss, R. \& Laurillard, D. (2006) Education 2.0? Towards an Educational Web 2.0, in Education 2.0? Designing the Web for Teaching and Learning. Institute of Education, London. Teaching and Learning Research Programme website. http: / www.tlrp.org/pub/documents/TELcomm.pdf

Thomas, K. (2009) The Rich Heritage of Democratic Education. Bristol: Futurelab.

Wegerif, R. (2002) Literature Review in Thinking Skills, Technology and Learning. Bristol: Futurelab. 
C.K. CHEUNG teaches at the Faculty of Education, University of Hong Kong. His research interests include media and information literacy, entrepreneurship education, and liberal studies. He is the founding chairman of the Hong Kong Association of Media Education and an expert in the area of media education. This article is based on the result of his research funded by the most prestigious research grant in Hong Kong. Correspondence: Dr C.K. Cheung, Faculty of Education, University of Hong Kong, Pokfulam, Hong Kong SAR, China (cheungck@,hkucc.hku.hk). 